Supporting Information

\title{
Role of grain size on magnon and phonon thermal transport in spin ladder compound $\mathrm{Ca}_{9} \mathrm{La}_{5} \mathrm{Cu}_{24} \mathrm{O}_{41}$
}

\author{
Shuchen Li, ${ }^{1 \#}$ Shucheng Guo, ${ }^{1 \#}$ Youming Xu, ${ }^{1}$ Jianshi Zhou, ${ }^{2}$ and Xi Chen ${ }^{1, *}$ \\ ${ }^{1}$ Department of Electrical and Computer Engineering, University of California, Riverside, \\ California 92521, USA \\ ${ }^{2}$ Materials Science and Engineering Program, Texas Materials Institute, The University of Texas \\ at Austin, Austin, Texas 78712, USA \\ ${ }^{\#}$ Contributed equally \\ *Email: $\underline{\text { xichen@ucr.edu }}$
}

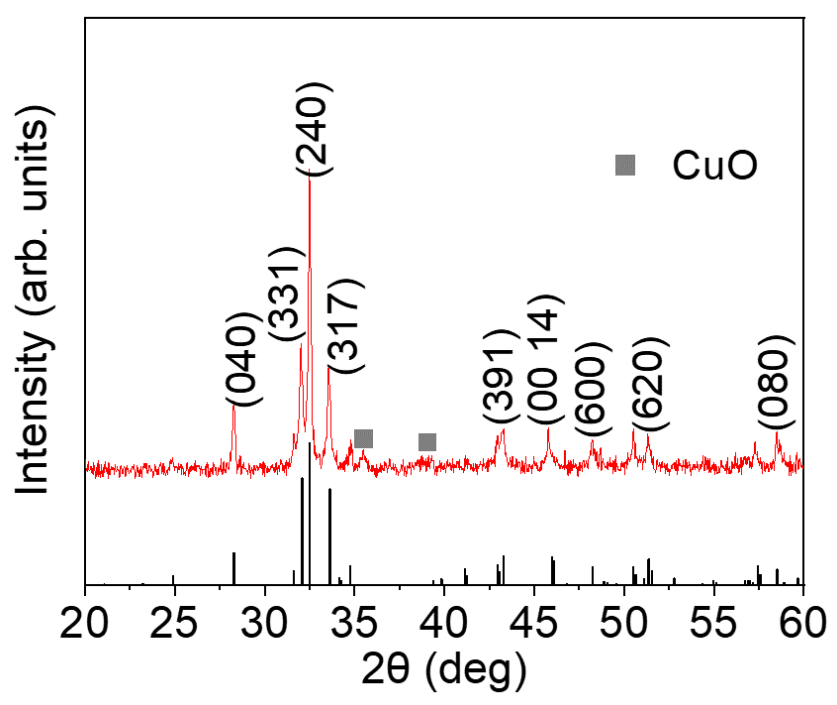

Figure S1. X-ray powder diffraction pattern of the $\mathrm{Ca}_{9} \mathrm{La}_{5} \mathrm{Cu}_{24} \mathrm{O}_{41}$ sample obtained by pulverizing a single crystal ingot. The peak index at the bottom is from PDF\# 84-1761. 


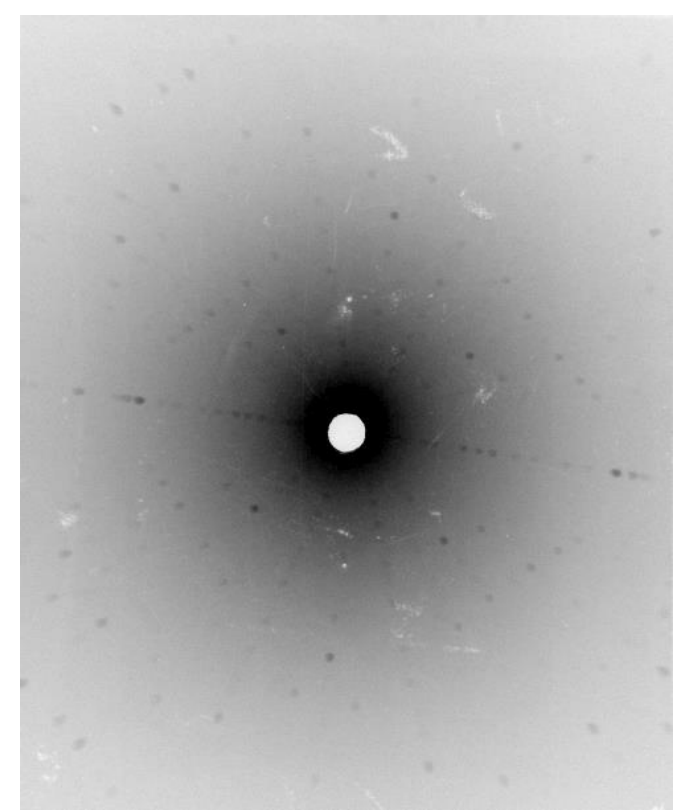

Figure S2. The Laue-back refection pattern of the $\mathrm{Ca}_{9} \mathrm{La}_{5} \mathrm{Cu}_{24} \mathrm{O}_{41}$ single crystal.

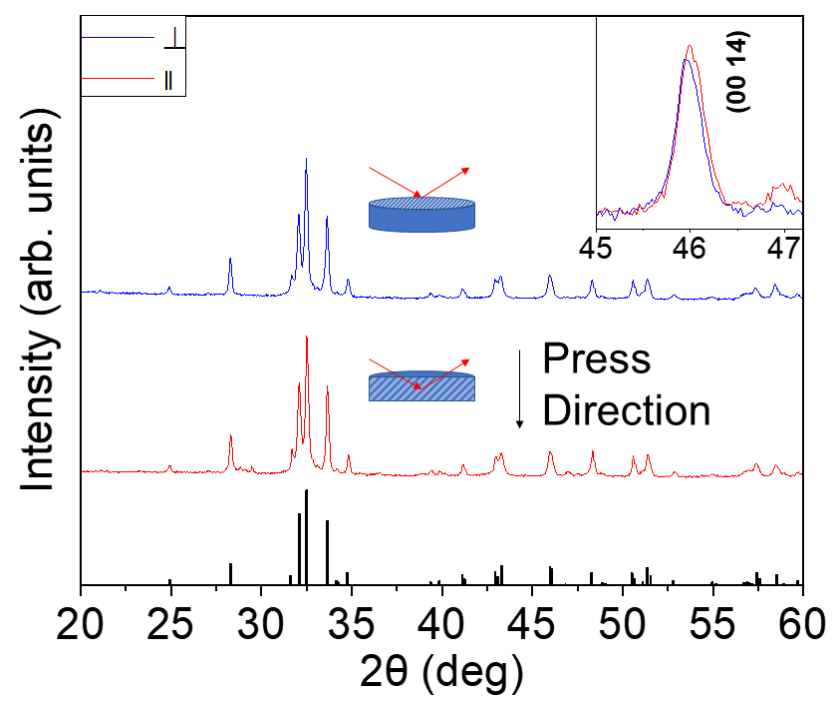

Figure S3. X-ray diffraction patterns of the w/o ball-milled $\mathrm{Ca}_{9} \mathrm{La}_{5} \mathrm{Cu}_{24} \mathrm{O}_{41}$ sample in both perpendicular $(\perp)$ and parallel directions $(I I)$ to the press direction. The inset on the right shows the $\left(\begin{array}{lll}0 & 0 & 14\end{array}\right)$ peak. 

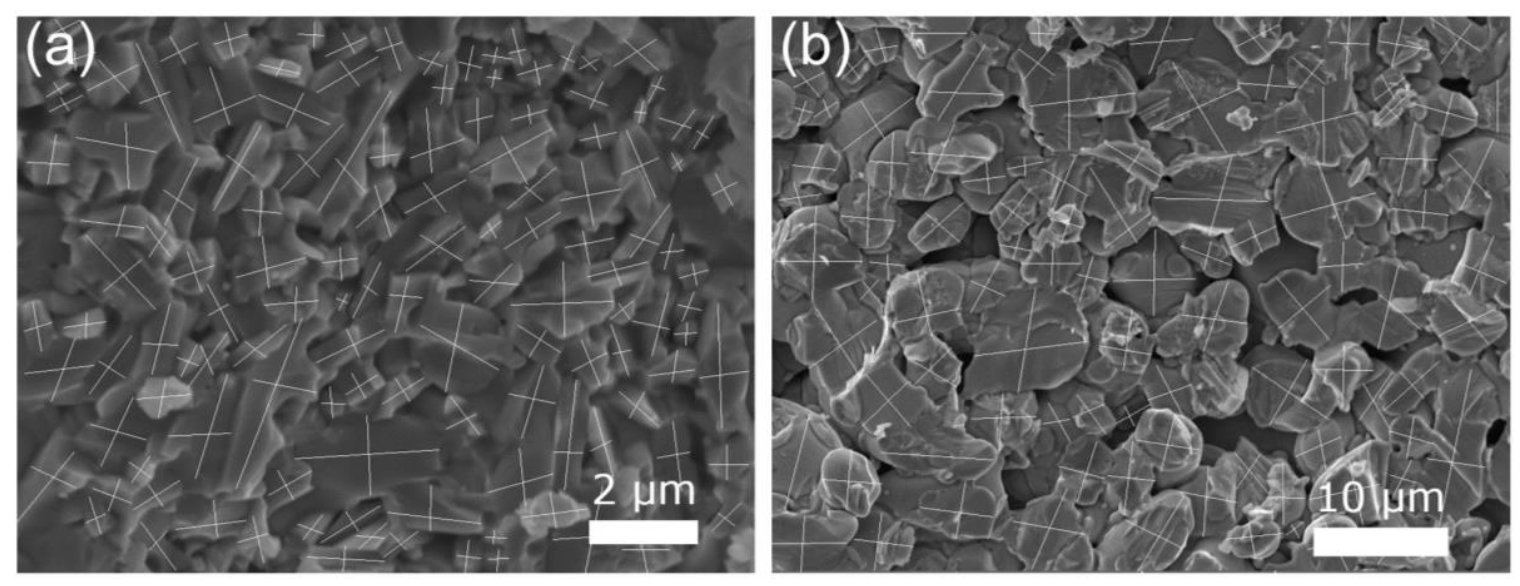

Figure S4. The analysis on SEM images to determine the average grain sizes of (a) ball-milled and (b) w/o ball-milled $\mathrm{Ca}_{9} \mathrm{La}_{5} \mathrm{Cu}_{24} \mathrm{O}_{41}$ samples. The white lines represent the grain sizes obtained for evaluation.

Table S1. Fitting parameters of the Debye model for four $\mathrm{Ca}_{9} \mathrm{La}_{5} \mathrm{Cu}_{24} \mathrm{O}_{41}$ samples.

\begin{tabular}{|c|c|c|c|c|}
\hline Sample & $\mathbf{A}\left(\mathrm{s}^{3}\right)$ & $B\left(\mathrm{~s} \cdot \mathrm{K}^{-3}\right)$ & $b(\mathrm{~K})$ & $L(\mathrm{~m})$ \\
\hline w/o BM, $\perp$ & $4.6536 \times 10^{-41}$ & $4.9275 \times 10^{-18}$ & 42.6647 & $3.4491 \times 10^{-6}$ \\
\hline w/o BM, // & $6.6129 \times 10^{-41}$ & $8.3799 \times 10^{-18}$ & 248.0668 & $1.2743 \times 10^{-6}$ \\
\hline $\mathrm{BM}, \perp$ & $2.2135 \times 10^{-41}$ & $1.0999 \times 10^{-17}$ & 149.9829 & $1.4264 \times 10^{-7}$ \\
\hline $\mathrm{BM}, / /$ & $3.1756 \times 10^{-41}$ & $3.9065 \times 10^{-17}$ & 456.4686 & $1.3485 \times 10^{-7}$ \\
\hline
\end{tabular}

